\title{
Graphenes as efficient metal-free Fenton catalysts
}

\author{
Juan C. Espinosa, ${ }^{[\mathrm{b}]}$ Sergio Navalón, ${ }^{[\mathrm{b}]}$ Ana Primo, ${ }^{[\mathrm{b}]}$ Mónica Moral,${ }^{[\mathrm{c}]}$ Javier Fernández Sanz, ${ }^{[\mathrm{c}]}$ \\ Mercedes Álvaro, ${ }^{[b]}$ Hermenegildo García ${ }^{*}[a]$
}

\begin{abstract}
Reduced graphene oxide ( $\mathrm{rGO}$ ) exhibits a high activity as Fenton catalyst with $\mathrm{HO}$ radicals generation efficiency over $82 \%$, and turnover numbers of 4,540 and 15,023 for phenol degradation and $\mathrm{H}_{2} \mathrm{O}_{2}$ consumption respectively. These values compare favorably with those achieved with transition metals, showing the potential of carbocatalysts for the Fenton reaction.
\end{abstract}

The vast majority of the chemical processes at industrial scale are catalytic and most of them use transition metals as active sites. ${ }^{[1]}$ For the sake of sustainability and competitiveness it is important to develop catalysts based on renewable materials. Carbocatalysis is a field that has appeared in the last few years aimed at developing metal-free catalysts based on carbon. ${ }^{[2-4]}$ Carbocatalysis has benefited largely from the availability of novel carbon allotropes. ${ }^{[3]}$ Particularly, due to the easy preparation together with their remarkable properties, $\left.{ }^{[5,} 6\right]$ graphenes (Gs) are increasingly attracting the interest as

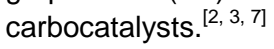

In the field of carbocatalysis, it would be challenging to demonstrate that materials based on carbon can act as catalysts for paradigmatic reactions promoted up to now exclusively by metals. Here it will be shown that Gs in the absence of any metal are highly efficient carbocatalysts for the Fenton reaction. Recently, we have shown that few-layers boron nitride nanoplatelets of about $20 \mathrm{~nm}$ lateral size can act as Fenton catalysts, although an excess of 11 equivalents of $\mathrm{H}_{2} \mathrm{O}_{2}$ was needed. ${ }^{[8]}$ Boron nitride is isostructural to graphene and, therefore, it is of interest to determine the catalytic activity of graphene materials for this reaction also. A related precedent has reported the decolorisation of Orange II by 200 equivalents excess of $\mathrm{H}_{2} \mathrm{O}_{2}$ using a reduced graphene oxide ( $\mathrm{rGO}$ ) obtained by ${ }^{60} \mathrm{Co} \gamma$-ray radiation of $\mathrm{GO}$ in a $\mathrm{N}_{2}$-purged sealed aqueous solution. It was claimed that the process involves the generation of $\mathrm{HO}$. radicals but no evidence for the generation of $\mathrm{HO}$ radicals was provided. ${ }^{[9]}$

The Fenton reaction consists in the generation of hydroxyl radicals $(\mathrm{HO})$ by reduction of $\mathrm{H}_{2} \mathrm{O}_{2}$ promoted by $\mathrm{Fe}^{2+}$ (Eqs (1) and (2)). ${ }^{[10,11]} \mathrm{HO}$ is after fluorine the most aggressive chemical species that can exist in water, attacking virtually to any organic

[a] Prof. H.Garcia

Instituto de Tecnología Química CSIC-UPV, Univ. Politécnica de Valencia, Av. de los Naranjos s/n, 46022 Valencia, Spain; Center of Excellence for Advanced Materials Research, King Abdulaziz University, Jeddah, Saudi Arabia.

E-mail: hgarcia@qim.upv.es

[b] J.C.Espinosa, Dr.S.Navalón, Dr. A. Primo, Prof.M.Álvaro, Instituto de Tecnología Química CSIC-UPV and Departamento de Química, Univ. Politécnica de Valencia, Av. de los Naranjos s/n, 46022 Valencia, Spain.

[c] Dr.M.Moral, Prof. J.F.Sanz

Departamento de Química Física, Universidad de Sevilla, 41012 Sevilla (Spain)

Supporting information for this article is given via a link at the end of the document. compound. The typical application of the Fenton reaction is the mineralization of organic pollutants in water by a $\mathrm{H}_{2} \mathrm{O}_{2}$ excess at acidic $\mathrm{pH}$ using stoichiometric amounts of $\mathrm{Fe}(\mathrm{II})$ salts. ${ }^{[11,12]}$

$$
\begin{aligned}
& \mathrm{Fe}^{2+}+\mathrm{H}_{2} \mathrm{O}_{2} \longrightarrow \mathrm{Fe}^{3+}+\mathrm{HO}^{-}+\mathrm{HO}^{-} \quad \text { Equation (1) } \\
& \mathrm{Fe}^{3+}+\mathrm{H}_{2} \mathrm{O}_{2} \longrightarrow \mathrm{Fe}^{2+}+\mathrm{HOO}^{-}+\mathrm{H}^{+} \quad \text { Equation (2) }
\end{aligned}
$$

Due to the concern on water quality, the Fenton reaction has gained importance as one of the key processes for waste water remediation. The target in this reaction has been the development of catalysts avoiding the need of stoichiometric amounts of $\mathrm{Fe}(\mathrm{II})$ salts and the efficient use of $\mathrm{H}_{2} \mathrm{O}_{2} \cdot{ }^{[13-15]}$ In general, catalytic Fenton processes use very large excess of $\mathrm{H}_{2} \mathrm{O}_{2}$, commonly over 1,000 equivalents of pollutant. ${ }^{[15]}$ It would be important to show that a carbocatalyst, in the absence of any metal, can efficiently promote the Fenton reaction with quasistoichiometric $\mathrm{H}_{2} \mathrm{O}_{2}$ amounts. Herein data will be presented showing that this goal has been achieved using affordable reduced graphene oxide (rGO) as catalyst. rGO does not deactivate, achieving turnover numbers (TON) as high as 4,540 and 15,023 of phenol disappearance and $\mathrm{H}_{2} \mathrm{O}_{2}$ consumption, respectively. Based on experimental data and density functional theory (DFT) calculations hydroquinone-like groups are proposed as active sites of the process.

To cover a range of possibilities, a series of Gs have been prepared to evaluate their activity as Fenton catalysts. The list includes $\mathrm{GO}{ }^{[16]}$ and $\mathrm{rGO},{ }^{[17]}$ as well as a $\mathrm{G}$ sample $(\mathrm{G})^{[16]}$ and a nitrogen doped $\mathrm{G}[(\mathrm{N}) \mathrm{G}]^{[16,18,19]}$ obtained by pyrolysis of alginate and chitosan, respectively. Precedents have shown that graphitic carbon residue from chitosan results after exfoliation in (N)G. ${ }^{[19]}$ In addition to $G$ and (N)G, two more boron-doped $G s$ namely $(B) G$ and $(B, N) G$ obtained by pyrolysis of borate esters of alginate and chitosan, respectively, were also prepared and evaluated. ${ }^{[16]}$ Pyrolysis of inorganic esters of saccharides leads to the incorporation as dopant of some heteroatom into the $G$ sheet. (B) G and (N)G exhibit opposite $p$ - and $n$ semiconducting properties, respectively, that can be relevant in the context of $\mathrm{H}_{2} \mathrm{O}_{2}$ activation. ${ }^{[13-16]}$ All the G-based materials included in the present study have been described and fully characterized earlier. ${ }^{[16-19]}$ Supplementary Table S1 collects the materials of the present study, their precursors and elemental composition. It should be commented that although the $G$ materials have been obtained from different precursors and the different preparation procedure could influence their catalytic behavior beyond their composition, it is expected that their main differences are the presence of dopant elements on the $G$ sheet. Spectroscopic properties of Gs, particularly Raman and X-ray photoelectron spectroscopy (XPS), crystallinity at the microscopic level and the single layer morphology of aqueous suspensions by atomic force microscopy (AFM) have been found coincident with literature data. ${ }^{[16-19]}$ All the materials exhibited the $2 D, G$ and $D$ bands in Raman spectroscopy with $G$ versus $D$ peak intensity 
ratio ranging from 1.3 to 1.6 (Supplementary Figure S1). XPS shows the presence of the expected doping elements, allowing determination of their percentage (Supplementary Figures S2S7 and Table S1). In addition, deconvolution of the C1s and N2p peaks shows for these two elements the proportion of the type of atoms present in the sample. Transmission electron microscopy (TEM) reveals high crystallinity of the samples (Supplementary Figure S8). The single layer morphology of doped Gs under reaction conditions was ascertained by AFM measuring the vertical height of $G$ sheets (Supplementary Figure S9). For the sake of comparison, commercial graphite, commercial multi-walled CNTs (MWCNTs) as well as purified and shortened MWCNTs were also included and tested as Fenton carbocatalysts (see Supplementary Table S2 and Figure S10 for their main physicochemical properties).

To evaluate the activity of Gs as Fenton carbocatalysts, phenol was selected as probe molecule, following its disappearance with time using 5.5 eq. of $\mathrm{H}_{2} \mathrm{O}_{2}$. Besides phenol disappearance, the temporal profile of $\mathrm{H}_{2} \mathrm{O}_{2}$ consumption was also followed for each reaction. In the literature there are abundant examples on the use of phenol as probe to evaluate the activity of metalcontaining catalysts, the main difference being the low $\mathrm{H}_{2} \mathrm{O}_{2}$ excess (5.5 eq.) employed here. ${ }^{[13-15]}$ The temporal profile of the reaction depends on the nature of $G$ (see selected examples in Figure 1 and Supplementary Figure S11). Phenol adsorption experiments show that $\mathrm{G}$ and active carbon (AC) are the solids with higher adsorption capacity ( $30 \%)$ followed by rGO (20\%), while adsorption on B and/or N-doped materials and GO is low $(<10 \%)$ (Figure S12a). The obtained adsorption values correlated with the expected strength of the $\pi-\pi$ intermolecular forces between phenol and the adsorbent as well as with the dispersability of the materials in water. In the case of $G, A C$ and rGO the combination of both the presence of oxygen functional groups $(<25 \%)$ and the aromatic character of the materials allow a good dispersability of the materials in water and the adsorption of phenol. ${ }^{[20]}$ In contrast, the hydrophobic character of B- or N-doped G makes more difficult their dispersability in water and, therefore, phenol adsorption. On the other hand, GO with a high population of oxygen functional groups ( $50 \%)$ disperses well in water, but its high hydrophilicity makes difficult phenol adsorption. In addition, a control in the absence of any catalyst shows that neither phenol nor $\mathrm{H}_{2} \mathrm{O}_{2}$ are decomposed in the same time (Supplementary Figure $\mathrm{S} 12 \mathrm{~b}$ ). Also a control of phenol degradation was attempted in the presence of $\mathrm{G}$, but in the absence of $\mathrm{H}_{2} \mathrm{O}_{2}$, observiong no phenol conversion under these conditions.
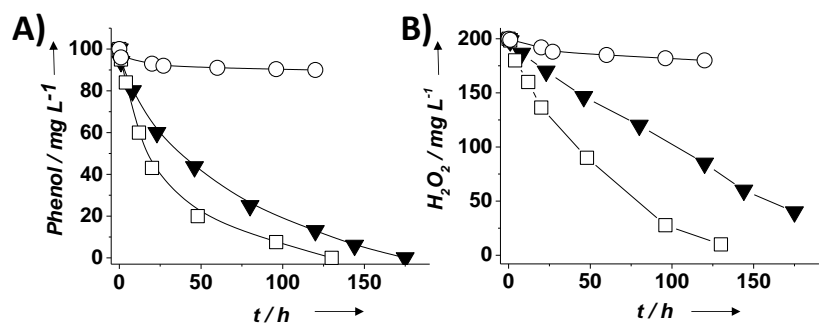

Figure 1. Temporal profiles of phenol degradation (A) and consumed $\mathrm{H}_{2} \mathrm{O}_{2}(B)$ using G-based catalysts. Legend: $\mathrm{G}(\square)$, rGO $(\boldsymbol{\nabla})$ and $\mathrm{GO}(\circ)$. Reaction conditions: Catalyst $\left(200 \mathrm{mg} \mathrm{L}^{-1}\right)$, phenol (100 mg L-1, $\left.1.06 \mathrm{mM}\right), \mathrm{H}_{2} \mathrm{O}_{2}(200 \mathrm{mg}$ $\left.\mathrm{L}^{-1}, 5.88 \mathrm{mM}\right), \mathrm{pH} 3,20 \stackrel{\circ}{ } \mathrm{C}$.

According to the results shown in Table 1, the ranking of activity as carbocatalyst is $\mathrm{G} \sim \mathrm{rGO}>(\mathrm{B}) \mathrm{G}>(\mathrm{B}, \mathrm{N}) \mathrm{G}>(\mathrm{N}) \mathrm{G}>\mathrm{GO}$. Since the catalytic activity of these graphene samples correspond to suspensions of single/few layers materials, this
Table 1. Summary of the catalytic activity for phenol degradation and $\mathrm{H}_{2} \mathrm{O}_{2}$ decomposition using Gs as carbocatalysts. ${ }^{a}$

\begin{tabular}{|c|c|c|c|c|c|c|c|}
\hline \multirow[t]{2}{*}{ Cat. } & & & $\mathrm{r}_{0} \_$phenol & $\mathrm{r}_{0} \mathrm{H}_{2} \mathrm{O}_{2}$ & \multirow{2}{*}{$\begin{array}{l}\mathrm{H}_{2} \mathrm{O}_{2} \text { to } \\
\text { phenol } \\
\text { molar } \\
\text { ratio }^{\mathrm{b}}\end{array}$} & & \multirow{2}{*}{$\begin{array}{l}\mathrm{Ea} \\
\mathrm{H}_{2} \mathrm{O}_{2} \\
(\mathrm{~kJ} \\
\left.\mathrm{mol}^{-1}\right)^{\mathrm{c}}\end{array}$} \\
\hline & $\begin{array}{l}\text { Conv. } \\
(\%)\end{array}$ & $\begin{array}{l}\text { Conv. } \\
(\%)\end{array}$ & $\begin{array}{l}\left(\mathrm{mM} \mathrm{h}^{-}\right. \\
\left.{ }^{1}\right)\end{array}$ & $\begin{array}{l}\left(\mathrm{mM} \mathrm{h}^{-}\right. \\
\left.{ }^{1}\right)\end{array}$ & & $\begin{array}{l}\text { phenol } \\
(\mathrm{kJ} \\
\mathrm{mol}^{-} \\
\left.{ }^{1}\right)^{\mathrm{c}}\end{array}$ & \\
\hline G & 100 & 95 & 0.042 & 0.147 & 5.2 & 31 & 31 \\
\hline rGO & 100 & 80 & 0.038 & 0.146 & 4.3 & 30 & 30 \\
\hline (B)G & 70 & 100 & 0.030 & 0.090 & 7.9 & 34 & 28 \\
\hline $\begin{array}{l}(\mathrm{N}, \mathrm{B} \\
\mathrm{G}^{-}\end{array}$ & 49 & 100 & 0.023 & 0.170 & 15.1 & 38 & 24 \\
\hline$(\mathrm{N}) \mathrm{G}$ & 18 & 100 & 0.011 & 1.765 & 23.9 & 39 & 18 \\
\hline GO & 7 & 3 & 0.002 & 0.009 & 5.5 & 54 & 48 \\
\hline
\end{tabular}

[a] Reaction conditions: Catalyst $\left(200 \mathrm{mg} \mathrm{L}^{-1}\right)$, phenol $\left(100 \mathrm{mg} \mathrm{L}^{-1}, 1.06\right.$ $\mathrm{mM}), \mathrm{H}_{2} \mathrm{O}_{2}\left(200 \mathrm{mg} \mathrm{L}^{-1}, 5.88 \mathrm{mM}\right), \mathrm{pH} \mathrm{3}, 20^{\circ} \mathrm{C}$, reaction time (Figure 1 and Supplementary Figure $\mathrm{S} 11$ ). [b] Determined at final reaction time up to $150 \mathrm{~h}$. [c] Determined from the corresponding Arrhenius plot.

order is probably not a reflection of differences in surface area, but, most probably, on the presence of appropriate active sites. For the best catalysts $\mathrm{G}$ and $\mathrm{rGO}$, the temporal profiles of phenol disappearance and $\mathrm{H}_{2} \mathrm{O}_{2}$ consumption coincide, indicating that $\mathrm{H}_{2} \mathrm{O}_{2}$ is consumed exclusively in phenol degradation and not in spurious self decomposition. On the other extreme, $(\mathrm{N}) \mathrm{G}$ decomposes $\mathrm{H}_{2} \mathrm{O}_{2}$ at much higher rate than phenol $\left(\mathrm{r}_{0} \mathrm{H}_{2} \mathrm{O}_{2} / \mathrm{r}_{0}\right.$ _phenol for (N)G 160) indicating that, in this case, other processes besides the Fenton reaction take place as for the vast majority of metal catalysts reported so far (see Table 1). ${ }^{[13-15]}$ The lack of catalytic activity of $\mathrm{GO}$ is remarkable and indicates that the oxygenated functional groups present on GO cannot act as active sites of the reaction. In the literature there are GO models that are compatible with the chemical analysis, ${ }^{13} \mathrm{C} N M R, I R$ and XP spectroscopic information for this material showing that the extreme oxygen content of this material (40 wt $\% \mathrm{O}$ or above) determines the presence of carboxylic acid groups, epoxides, ketones and other oxygenated functionalities with almost complete absence of aromaticity and conjugated $\mathrm{C}=\mathrm{C}$ double bonds. ${ }^{[6,21]}$

In the case of $(B) G$, phenol disappearance exhibits an induction period, not observed for $\mathrm{H}_{2} \mathrm{O}_{2}$ consumption (Supplementary Figure S11 and S13), attributable to B leaching as revealed by ICP measurements and by theoretical calculations (Supplementary Figures S13 and S14). Considering the catalytic data, rGO was the most convenient and efficient carbocatalyst for the Fenton reaction.

Analysis of the phenol decomposition products shows that hydroquinone, catechol and $p$-benzoquinone are formed (Figure 2). According to the accepted Fenton reaction mechanism, one equivalent of phenol consumes one equivalent of $\mathrm{HO}$ radicals to form catechol and hydroquinone and, then, at least two more equivalents to form $p$-benzoquinone and dicarboxylic acids. Therefore, the minimum consumption will be 3 eq. of $\mathrm{H}_{2} \mathrm{O}_{2}$ per mole of phenol disappeared. The time-conversion plots for phenol disappearance and $\mathrm{H}_{2} \mathrm{O}_{2}$ consumption using $\mathrm{rGO}$ as catalyst (Figure 1) correspond to a very efficient catalyst, $r_{0}$ $\mathrm{H}_{2} \mathrm{O}_{2} / \mathrm{r}_{0}$ _phenol ratio being 3.8 , indicating that at least $79 \%$ of $\mathrm{H}_{2} \mathrm{O}_{2}$ decomposes generating $\mathrm{HO}$ radicals (see also 
Supplementary Figure S15). Furthermore, using rGO as catalyst a $\mathrm{H}_{2} \mathrm{O}_{2}$ to phenol molar ratio of 5.5 was sufficient for full degradation of phenol (Supplementary Figure S16), and its more toxic intermediates hydroquinone, $p$-benzoquinone and catechol (Supplementary Figures S17, S18). Additional experiments were carried out with hydroquinone and catechol as starting materials. As expected, it was observed that also these isomeric dihydroxybenzenes become degraded under the standard conditions employed in this work (footnote a in Table 1) (see Figure $\mathrm{S} 18$ in the supporting information).

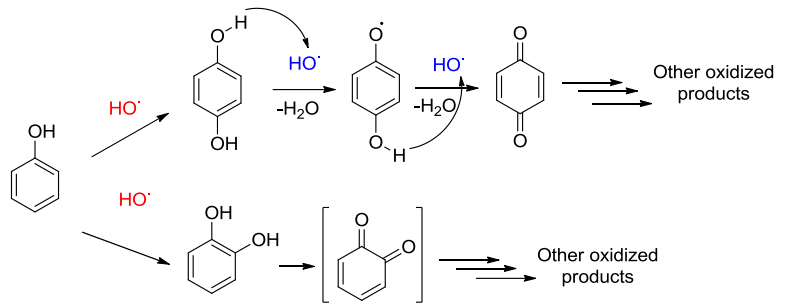

HO as electrophile HO as hydrogen abstraction agent

Figure 2. Degradation pathway of phenol by hydroxyl radicals.

One of the hallmarks of Fenton reaction is its strong dependence with $\mathrm{pH}$. In the present case it was determined that rGO can operate in a narrow pH interval 2-4 (Supplementary Figure S19). Lower $\mathrm{pH}$ values should protonate $\mathrm{H}_{2} \mathrm{O}_{2}$ disfavoring the formation of $\mathrm{HO}$ radicals (Eq. (3)). pH values higher than 3 , however, would increase the concentration of hydroperoxy anions leading to a decrease of both $\mathrm{H}_{2} \mathrm{O}_{2}$ and $\mathrm{HO}$ radical concentrations (Eqs. (5) and (6)). ${ }^{[2]}$ Also, increasing the $\mathrm{pH}$ decreases the oxidation potential of $\mathrm{HO}$ radicals.

Stability and maximum productivity of a catalyst is crucially important. To prove stability and determine productivity of rGO a series of consecutive reuses were performed in which the ratio phenol $\left(1,000 \mathrm{mg} \mathrm{L}^{-1}\right)$ to $\mathrm{rGO}\left(50 \mathrm{mg} \mathrm{L}^{-1}\right)$ was increased by a factor of 40 , allowing the reaction to run for long times (Supplementary Figure S20). Five consecutive reuses reaching as high as 3.95 and $4.73 \mathrm{~g} \mathrm{~L}^{-1}$ of phenol and $\mathrm{H}_{2} \mathrm{O}_{2}$, respectively, reacted with only $50 \mathrm{mg} \mathrm{L}^{-1}$ of $\mathrm{rGO}$ (one forth the rGO amount employed in the general reaction procedure) were measured. The slight increase of catalytic activity even observed upon reusing rGO was attributed to the better rGO dispersability in water upon reuse due to mild rGO hydroxylation (Supplementary Figure S21). It should be commented that the residual oxygen content of rGO (about $15 \mathrm{wt} \%$ ) makes possible its dispersion in aqueous phase by sonication to test its catalytic activity. Normally while GO is highly dispersible in water due to its hydrophilicity, reduction of $\mathrm{GO}$ to $\mathrm{rGO}$ decreases considerably the hydrophilicity. In the present case, the residual $O$ content of rGO makes this material still dispersible in water. ${ }^{[20]}$ However, after its use as Fenton catalysts, it was noticed that just stirring or light sonication was sufficient to obtain a permanent suspension of used rGO. Importantly, a $\mathrm{H}_{2} \mathrm{O}_{2}$ to phenol mol ratio of only 3.3 was needed for complete phenol degradation. Again, in the absence of catalyst the reaction does not take place (Supplementary Figure S20). Unfortunately, the unknown nature of the active centers in rGO precludes determination of turnover number (TON). Nevertheless, it has been established by XPS that quinone centers in rGO can be about 2 to $5 \mathrm{wt} \%{ }^{[23]}$ As we will comment below, quinone centers are possible active sites and the percentage can be estimated based on the deconvolution of the experimental $\mathrm{C} 1 \mathrm{~s}$ peak to individual components and quantification of the percentage of $\mathrm{C}=\mathrm{O}$ carbons. Speculating that the percentage of active centers is in this proportion based on XPS quantification of the fraction of $\mathrm{C}=\mathrm{O}$, then, an estimation of the accumulated TON achieved with rGO as carbocatalyst would be 4,540 and 15,023 for phenol disappearance and $\mathrm{H}_{2} \mathrm{O}_{2}$ consumption, respectively. This TON is higher than those reported for many transition metal Fenton catalysts, ${ }^{[13,15]}$ although is about two orders of magnitude lower than that reported for the best Fenton catalyst based on supported Au NPs $(458,459) .{ }^{[24,25]}$ Carbocatalysts based on G are, however, still open to further optimization by material engineering and the accumulated TON value measured is just the first estimation in this area. Graphene samples specially engineered for optimization of the quinone-like content instead of a few percents should exhibit an optimal catalytic activity.

It should be commented that besides hydroquinone/quinone like redox pairs, there could also be other possible sites on doped $\mathrm{G}$ to promote the reaction. In the case of (N)G we have seen that there is a considerable decomposition of $\mathrm{H}_{2} \mathrm{O}_{2}$ that is not associated to the generation of $\mathrm{HO}$. radicals, in accordance with previous reports in the literature. ${ }^{[26]}$ These sites are probably some of the different types of $\mathrm{N}$ atoms present in (N)G. In the case of (B)G, it has been found that $B$ atoms are not stable on $\mathrm{G}$ and decompose spuriously $\mathrm{H}_{2} \mathrm{O}_{2}$ while the $\mathrm{B}$ atoms are leached. This indicates again that $\mathrm{B}$ atoms are sites for $\mathrm{H}_{2} \mathrm{O}_{2}$ decomposition.

Importantly, the possibility that $\mathrm{Mn}$ traces were responsible for the observed activity during the productivity tests was dismissed by performing additional productivity experiments in which $\mathrm{Mn}^{2+}$ ions were added on purpose in the range of concentration of ppms $(50 \mu \mathrm{g})$, both in the presence and in the absence of rGO and observing a lack of activity (in the absence of $\mathrm{rGO}$ ) or no variation with respect to the use of $\mathrm{rGO}(\mathrm{Mn}$ impurity content $<100$ ppms) (Supplementary Figure S22). It should also be commented that GO (not rGO) is the sample with the highest $\mathrm{Mn}^{2+}$ contamination (150 ppm) and, is, however, the less active (Table 1). Thus, there is no apparent relationship between the metal impurities and activity.

Activation energy (Ea) of phenol disappearance and $\mathrm{H}_{2} \mathrm{O}_{2}$ decomposition was estimated for the series of Gs by performing the reaction at different temperatures from 20 to $80 \stackrel{\circ}{\circ}$ (Table 1 , Figure 3 and Supplementary Figures S23-S27). It was observed that Ea for the most efficient catalyst for phenol disappearance and $\mathrm{H}_{2} \mathrm{O}_{2}$ decomposition has a coincident value of $30 \mathrm{~kJ} \mathrm{~mol}^{-1}$.

$$
\begin{aligned}
& \text { pH }<3 \\
& \mathrm{H}_{2} \mathrm{O}_{2}+\mathrm{H}^{+} \longrightarrow \mathrm{H}_{3} \mathrm{O}_{2}^{+} \quad \text { Equation (3) } \\
& \mathrm{HO}+\mathrm{H}^{+}+\mathrm{e}^{-} \quad \mathrm{H}_{2} \mathrm{O} \quad \text { Equation (4) }
\end{aligned}
$$

$\mathbf{p H}>\mathbf{3}$

$$
\begin{array}{rll}
\mathrm{H}_{2} \mathrm{O}_{2}+\mathrm{HOO}^{-} & \mathrm{H}_{2} \mathrm{O}+\mathrm{O}_{2}+\mathrm{HO}^{\circ} & \text { Equation (5) } \\
\mathrm{HO}^{-}+\mathrm{HOO}^{-} & \mathrm{H}_{2} \mathrm{O}+\mathrm{O}_{2}{ }^{-} & \text {Equation (6) }
\end{array}
$$
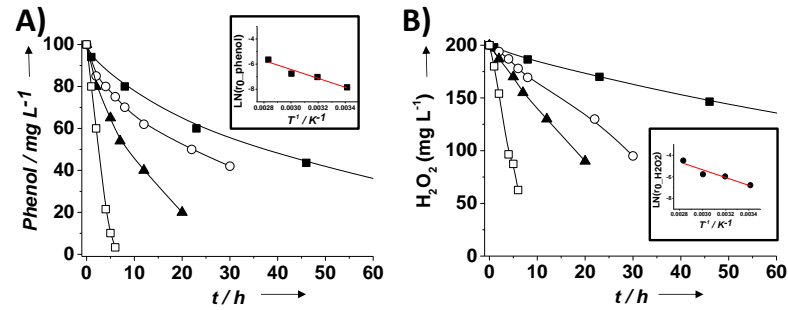

Figure 3. (A) Phenol degradation and (B) $\mathrm{H}_{2} \mathrm{O}_{2}$ decomposition as a function of the reaction temperature using $\mathrm{rGO}$ as catalyst. The insets show the Arrhenius plot for both processes. Reaction conditions: Catalyst $\left(200 \mathrm{mg} \mathrm{L}^{-1}\right)$, phenol 
(100 mg L $\left.{ }^{-1}, 1.06 \mathrm{mM}\right), \mathrm{H}_{2} \mathrm{O}_{2}\left(200 \mathrm{mg} \mathrm{L}^{-1}, 5.88 \mathrm{mM}\right), \mathrm{pH}$ 3. Legend: $80^{\circ} \mathrm{C}(\square)$

$60^{\circ} \mathrm{C}(\boldsymbol{\Delta}), 40^{\circ} \mathrm{C}(\circ)$ and $20^{\circ} \mathrm{C}(\mathbf{\bullet})$.

The fact that both processes exhibit the same Ea agrees with the exclusive operation of a Fenton reaction in which generation of $\mathrm{HO}$ radical from $\mathrm{H}_{2} \mathrm{O}_{2}$ will be the rate determining step, responsible for the Ea. Once $\mathrm{HO}$ radicals are generated, they will react with phenol or dihydroxybenzenes essentially without energy barrier and, consequently, $\mathrm{Ea}$ of phenol degradation and generation of $\mathrm{HO}$ radicals would coincide. Also remarkable is that the Ea value is relatively low and comparable with that reported for the most efficient heterogeneous Fenton catalyst based on Au NPs supported on D. ${ }^{[25]}$ For less efficient carbocatalysts, such as $(\mathrm{N}) \mathrm{G}$, the $\mathrm{Ea}$ values of phenol degradation are higher than those of $\mathrm{H}_{2} \mathrm{O}_{2}$ decomposition, implying that the barrier to decompose $\mathrm{H}_{2} \mathrm{O}_{2}$ is lower and the attack to phenol requires additional activation. This mismatch between lower $\mathrm{Ea}$ for $\mathrm{H}_{2} \mathrm{O}_{2}$ decomposition and higher Ea for phenol disappearance increases as the efficiency of the catalyst to generate $\mathrm{HO}$ radicals decreases.

The efficiency of $\mathrm{rGO}$ to generate $\mathrm{HO}$ radicals in the decomposition of $\mathrm{H}_{2} \mathrm{O}_{2}$ can be estimated by performing an experiment in which phenol is in a large excess respect to $\mathrm{H}_{2} \mathrm{O}_{2}$. These conditions using a large excess of phenol are the opposite to those generally used when the target is to degrade phenol, but under these reverse conditions most of the $\mathrm{HO}$. radicals would attack preferentially phenol forming catechol, hydroquinone and $p$-benzoquinone and by quantifying these products with respect to $\mathrm{H}_{2} \mathrm{O}_{2}$ consumption the percentage of decomposed $\mathrm{H}_{2} \mathrm{O}_{2}$ that has generated $\mathrm{HO}$ radicals can be indirectly determined, assuming the equations appearing in Figure 2. Measurements under these conditions have established that at least $82 \%$ of $\mathrm{H}_{2} \mathrm{O}_{2}$ consumption is correlated with the transformation of phenol to catechol, hydroquinone and p-benzoquinone (Supplementary Figure S18a and S28). Obviously, as the reaction proceeds this efficiency apparently decreases due to the reaction of $\mathrm{HO}$ radicals with the primary products rather than with phenol. This efficiency in the generation of $\mathrm{HO}$ radical is remarkably high and justifies why there is no need of a large $\mathrm{H}_{2} \mathrm{O}_{2}$ excess for phenol degradation.

Evidence of the generation of $\mathrm{HO}$ radicals was indirectly obtained by dimethylsufoxide (DMSO) quenching of phenol degradation. It is known that DMSO reacts readily with $\mathrm{HO}$. radicals leading to the formation of $\mathrm{CH}_{3}$ radicals and methanesulfinic acid (Equation 7). ${ }^{[2]}$ DMSO quenching experiments under appropriate conditions using rGO as catalyst shows that phenol degradation is completely inhibited by ten times molar excess of DMSO, thus, proving indirectly the mechanism of the Fenton reaction (Supplementary Figure S29).

$$
\left(\mathrm{CH}_{3}\right)_{2} \mathrm{SO}+{ }^{\circ} \mathrm{OH} \longrightarrow \mathrm{CH}_{3} \mathrm{SO}_{2} \mathrm{H}+\mathrm{CH}_{3} \cdot \text { Equation (7) }
$$

Another evidence for the generation of $\mathrm{HO}$ radicals has been obtained by electron paramagnetic resonance (EPR) spectroscopy using phenyl- $\alpha$-tert-butyl nitrone (PBN) as trapping agent. The EPR spectra of the corresponding PBN-(OH) adduct radical were recorded (Figure 4). This EPR spectrum with fine structure giving structural information constitutes a firm evidence of $\mathrm{HO}$ radicals generation from $\mathrm{H}_{2} \mathrm{O}_{2}$ by rGO. It should be, however, commented that EPR spectroscopy using PBN as $\mathrm{HO}$. radical trap is not a suitable procedure to quantify the percentage of $\mathrm{HO}$. radical generated by each $\mathrm{G}$ catalyst due to degradation of PBN by $\mathrm{HO}$ - radicals. Thus, $\mathrm{PBN}$ trapping of $\mathrm{HO}$. can only be taken as a procedure for $\mathrm{HO}$. detection.

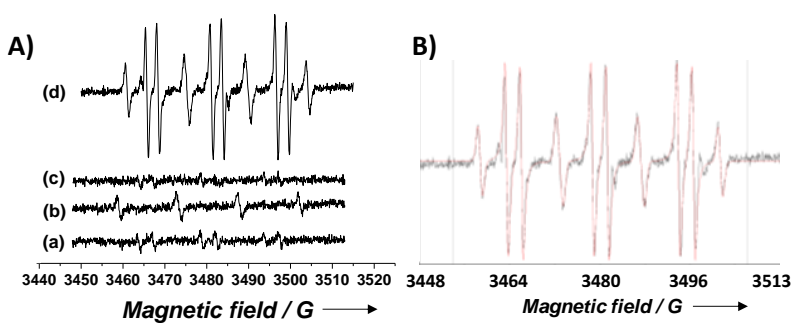

Figure 4. (A) EPR spectra of (a) $\mathrm{PBN}+\mathrm{H}_{2} \mathrm{O}$; (b) $\mathrm{rGO}+\mathrm{PBN}$; (c) $\mathrm{PBN}+\mathrm{H}_{2} \mathrm{O}_{2}$; (d) $\mathrm{rGO}+\mathrm{H}_{2} \mathrm{O}_{2}+\mathrm{PBN}$. (B) EPR spectra of sample (d) and its fitting (red lines) considering the $\mathrm{PBN}-\mathrm{OH}$ adduct $\left(\mathrm{AG}_{\mathrm{N}}=15.5\right.$ and $\left.\mathrm{AG}_{\mathrm{H}}=2.7\right)$ and tert-butyl aminoxyl $\left(A G_{N}=14.58\right.$ and $\left.A G_{H}=13.90\right)$ coinciding with the reported values in the literature. EPR reaction conditions. $\mathrm{rGO}\left(200 \mathrm{mg} \mathrm{L}^{-1}\right), \mathrm{PBN}\left(1,041 \mathrm{mg} \mathrm{L}^{-1}\right.$, $5.88 \mathrm{mM}), \mathrm{PBN}$ to $\mathrm{H}_{2} \mathrm{O}_{2}$ molar ratio $1: 1, \mathrm{pH} 3,45$ min reaction time.

To provide some conceptual framework to rationalize the catalytic activity of Gs for the Fenton reaction, basic DFT calculations with simple models of hydroquinone moieties that could be present in $\mathrm{G}$ were performed. It is pertinent to comment that prior DFT calculations have predicted that graphenic $\mathrm{N}$ atoms on $\mathrm{G}$ (case of $(\mathrm{N}) \mathrm{G}$ ) decompose $\mathrm{H}_{2} \mathrm{O}_{2}$ to $\mathrm{H}_{2} \mathrm{O}$ via $\mathrm{N}-\mathrm{OH}$ intermediates. ${ }^{[26]}$ In line with these calculations that were not supported experimentally, herein it has been observed that $(N) G$ performs a considerably degree of $\mathrm{H}_{2} \mathrm{O}_{2}$ decomposition without generating free $\mathrm{HO}$ radicals in solution.

Our DFT study started calculating the feasibility of $\mathrm{HO}$ generation by hydroquinone $\mathrm{H}_{2} \mathrm{O}_{2}$ reduction (Figure 5). The calculations indicate that the process is uphill by $\sim 2 \mathrm{eV}$ in a difference of terms about $130 \mathrm{eV}$. Similar calculations predict that the presence of electron donor substituents in the aromatic ring decreases the endoergonicity of the process to about 0.16 $\mathrm{eV}$. Another model of hydroquinone-like moieties present on $\mathrm{G}$ having condensed benzopyrene units shows again that $\mathrm{HO}$ generation from $\mathrm{H}_{2} \mathrm{O}_{2}$ reduction of hydroquinone moieties should be slightly unfavorable by $1.1 \mathrm{eV}$ in a difference of terms about $400 \mathrm{eV}$. Overall these DFT calculations indicate that the process of $\mathrm{HO}$ generation from hydroquinones is quasi neutral from the energy viewpoint, this situation being ideal for site reversibility. It is clear that further calculations are necessary using model structures of $G$ and addressing the various steps in the reaction mechanism for a better understanding of the origin of the Fenton-like catalytic activity on Gs.

To provide some support to this prediction about the nature of the redox sites on $\mathrm{G}$, we selected $p$-benzoquinone and hydroquinone as simple model molecules present in rGO structure. Using these two molecules as organocatalysts the catalytic activity for both phenol degradation and $\mathrm{H}_{2} \mathrm{O}_{2}$ decomposition was evaluated (Supplementary Figures S30-S32), observing that both organocatalyst behaves similarly promoting the Fenton reaction. In addition, DMSO quenching and PBN trapping (Supplementary Figure $\mathrm{S} 32$ and $\mathrm{S} 33$ ) of $\mathrm{HO}$ radicals also confirm that $\mathrm{HO}$ are generated by reduction of $\mathrm{H}_{2} \mathrm{O}_{2}$ with hydroquinone. Similarly, 2-methoxyhydroquinone and 2methylhydroquinone as organocatalysts also generate $\mathrm{HO}$ radicals by reduction of $\mathrm{H}_{2} \mathrm{O}_{2}$, as demonstrated by DMSO quenching experiments (Supplementary Figure S34), at an enhanced rate than the parent hydroquinone, in good agreement with the predicted influence of electron donor substituents (Supplementary Figure S34). 

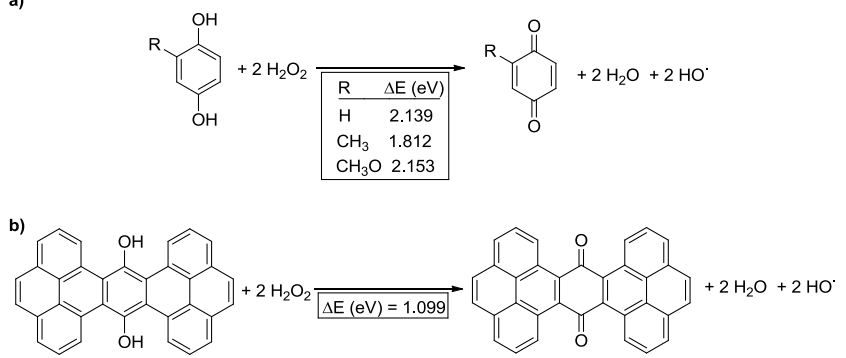

Figure 5. Energy variation (DE) in the generation of $\mathrm{HO}$ radicals from $\mathrm{H}_{2} \mathrm{O}_{2}$ by hydroquinones as models of $\mathrm{G}$ active sites.

Finally, we evaluated the catalytic activity of rGO versus that of other carbonaceous materials such as graphite, MWCNT and derivatives. It was found that other carbon materials also exhibit catalytic activity for the Fenton degradation of phenol (Supplementary Figure S35). Particularly notable is the catalytic activity of purified, short CNTs that for phenol degradation is similar to that of rGO. It should be noted, however, that CNTs consume in the process a significantly larger amount of $\mathrm{H}_{2} \mathrm{O}_{2}$ and, therefore, still remains that the catalytic activity of $\mathrm{rGO}$ is much better compared to that of graphite and MWCNTs in terms of high efficiency in $\mathrm{HO}^{\prime}$ generation. As commented earlier, the optimal Fenton catalyst should exhibit complete selectivity of $\mathrm{H}_{2} \mathrm{O}_{2}$ decomposition into $\mathrm{OH}$. radicals and this requires that $\mathrm{E}_{\mathrm{a}}$ for phenol consumption and $\mathrm{H}_{2} \mathrm{O}_{2}$ decomposition should be equal and that the number of equivalents of $\mathrm{H}_{2} \mathrm{O}_{2}$ consumed should be minimal and close to the theoretical value. With regard to the catalytic activity of graphite, it has been possible to detect the presence of $G$ at final reaction times. Thus, it could be probable that graphite acts as precursor of active $G$. This hypothesis is consistent with the observation in the timeconversion plot of an initial induction period (see Figure S34 in the supporting information). Another point to be noted is the benefits of oxidative treatment of MWCNT, a fact that can be attributed to the generation of oxygenated functional groups such quinone and/or hydroquinone-like groups (Supplementary Table S2 and Supplementary Figure S10). ${ }^{[28]}$ It should be noted, however, that the not all the oxygenated functional groups should be active centers for Fenton-like $\mathrm{H}_{2} \mathrm{O}_{2}$ decomposition and that according to our proposal only those hydroquinone/quinone subunits of adequate redox potential would act sites for $\mathrm{HO}$. radical generation, while other oxygenate functional groups can decompose spuriously $\mathrm{H}_{2} \mathrm{O}_{2}$ into $\mathrm{O}_{2}$ without forming $\mathrm{HO}$. radicals. In contrast, the use of $\mathrm{AC}$ as carbocatalyst resulted in negligible activity for phenol degradation, while promoting the spurious decomposition of $\mathrm{H}_{2} \mathrm{O}_{2}$. The apparent phenol removal observed for AC corresponds to adsorption (Figure S35). In any case, the data obtained on the general activity of carbon materials (particularly with graphene walls) combined with the previously commented activity of $p$-benzoquinone and substituted hydroquinones show that the concept of carbocatalysis for the Fenton reaction is of universal application and can lead to develop a vast number of metal-free catalyst. For comparison, under the present conditions a noble metal benchmark catalyst based on Au NPs (1 wt\%; $10.8 \mathrm{~nm}$ average) supported on Fenton-treated diamond nanoparticles promotes the complete phenol degradation by $\mathrm{H}_{2} \mathrm{O}_{2}$ as oxidant at $\mathrm{pH} 4$ in about $50 \mathrm{~h}^{\text {[24] }}$. Although less active, herefore, $\mathrm{G}$ or $\mathrm{rGO}$ as metal free-catalysts can achieve this transformation in about $150 \mathrm{~h}$ at $\mathrm{pH} 3$ (Figure 1) and could represent an example of replacing noble metals by other cost-effective carbocatalysts.
In conclusion, in the present work we have shown that Gs can act as carbocatalysts for the Fenton generation of $\mathrm{HO}$ from $\mathrm{H}_{2} \mathrm{O}_{2}$, a reaction that, up to now, has been reported exclusively using transition metal catalysts. The composition and structure of the $\mathrm{G}$ sample influence its catalytic activity that is maximal for rGO and $\mathrm{G}$. In these cases a minimum selectivity towards $\mathrm{HO}$ formation of $82 \%$ was estimated and very large productivity values with minimal deactivation upon reuse and optimal $\mathrm{H}_{2} \mathrm{O}_{2}$ consumption have been established. It has been shown that the concept of metal-free catalysts for Fenton reaction is universal and can be based on those materials that contain certain oxygenated functional groups that act as redox centers with the correct potential to oxidize and reduce $\mathrm{H}_{2} \mathrm{O}_{2}$.

\section{Acknowledgements}

Financial support by Generalidad Valenciana (GV/2013/040 and Prometeo 2012/2013) is gratefully acknowledged. Spanish Ministry of Economy and Competitiveness is also thanked for funding (Severo Ochoa and CTQ2012-32315).

Keywords: graphene - carbocatalysis - metal-free catalyst • heterogeneous Fenton reaction $\bullet$ hydroxyl radicals in water

[1] M. Stratakis, H. Garcia, Chem. Rev. 2012, 112, 4469 4506; R. Jana, T. P. Pathak, M. S. Sigman, Chem. Rev. 2011, 111, 1417-1492; T. Punniyamurthy, S. Velusamy, Iqbal, J., Chem. Rev. 2005, 105, 2329-2363; S. Navalon M. Alvaro, H. Garcia, ChemCatChem 2013, 5, 3460-3480. D. R. Dreyer, C. W. Bielawski, Chem. Sci. 2011, 2, 12331240; C. Su, K. P. Loh, Acc. Chem. Res. 2013, 46, 2275 2285; D. S. Su, S. Perathoner, G. Centi, Chem. Rev. 2013, 113, 5782-5816.

[3] S. Navalon, A. Dhakshinamoorthy, M. Alvaro, H. Garcia, Chem. Rev. 2014, 114, 6179-6212.

[4] X.-K. Kong, C.-L. Chen, Q.-W. Chen, Chem. Soc. Rev. 2014, 43, 2841-2857.

[5] D. R. Dreyer, R. S. Ruoff, C. W. Bielawski, Angew. Chem. Int. Ed. 2010, 49, 9336 - 9344.

[6] D. R. Dreyer, S. Park, C. W. Bielawski, R. S. Ruoff, Chem. Soc. Rev. 2010, 39, 228-240.

[7] A. Schaetz, Zeltner, M., Stark, W.J., ACS Catal. 2012, 2, 1267-1284; D. R. Dreyer, H.-P. Jia, C. W. Bielawski, Angew. Chem. Int. Ed. 2010, 49, 6813 -6816.

[8] A. Primo, S. Navalón, A. M. Asiri, H. García, Chem. Eur. J. 2015, 21, 324-330.

[9] Y. Zhao, W.-F. Chen, C.-F. Yuan, Z.-Y. Zhu, L.-F. Yan, Chin. J. Chem. Phys. 2012, 25 335-338.

[10] J. J. Pignatello, E. Oliveros, A. Mackay, Crit. Rev. Environ. Sci. Technol. 2006, 36, 1-84.

[11] E. Neyens, Baeyens, J., J. Hazard. Mater. 2003, 98, 33-50.

[12] M. Pera-Titus, V. García-Molina, M. A. Baños, J. Giménez, S. Esplugas, Appl. Catal. B-Environ. 2004, 47, 219-256.

[13] S. Navalon, M. Alvaro, H. Garcia, Appl. Catal. B-Environ 2010, 99, 1-26.

[14] S. Navalon, A. Dhakshinamoorthy, M. Alvaro, H. Garcia, ChemSusChem 2011, 4, 1712-1730.

[15] A. Dhakshinamoorthy, S. Navalon, M. Alvaro, H. Garcia, ChemSusChem 2012, 5, 46-64. 
[16] A. Dhakshinamoorthy, A. Primo, P. Concepción, M. Alvaro, H. García, Chem. Eur. J. 2013, 19, 7547-7554.

[17] L.-Y. Meng, S.-J. Park, Adv. Mater. Res. 2010, 123-125, 787-790; C. D. Zangmeister, Chem.Mater. 2010, 22, 56255629; M. Jin, H.-Y. Jeong, T.-H. Kim, K. P. So, Y. Cui, W. J. Yu, E. J. Ra, Y. H. Lee, J. Phys. D: Appl. Phys. 2010, 43, 275402.

[18] A. Primo, P. Atienzar, E. Sanchez, J. M. Delgado, H. García, Chem. Commun. 2012, 48, 9254-9256.

[19] A. Primo, E. Sanchez, J. M. Delgado, H. García, Carbon 2014, 68, 777-783.

[20] D. Koniosa, M. M. Stylianakis, E. Stratakis, E. Kymakis, J. Colloid. Interf. Sci. 2014, 430, 108-112.

[21] D. R. Dreyer, A. D. Todd, C. W. Bielawski, Chem. Soc. Rev. 2014, 43, 5288-5301.

[22] A. Mahmood, S. Ali, Saleem,, H. H., T., Asian J. Chem. 2011, 23, 3875-3878; C. M. Silva, P. L. Silva, J. R. Pliego, Int. J. Quantum Chem. 2014, 114, 501-507; J.-H. Sun, S.P. Sun, G.-L. Wang, L.-P. Qiao, Dyes Pigments 2007, 74, 647-652.

[23] A. Bagri, C. Mattevi, M. Acik, Y. J. Chabal, M. Chhowalla, S. V.B., Nat. Chem. 2010, 2, 581-587; S. Choudhary, H. P. Mungse, O. P. Khatri, Chem. Asian J. 2013, 8, 2070-2078.

[24] S. Navalon, Martin, R., Alvaro, M., Garcia, H., Angew. Chem. Int. Ed. 2010, 49, 8403-8407.

[25] R. Martin, Navalon, S., Delgado, J.J., Calvino, J.J., Alvaro, M., Garcia, H., Chem. Eur. J. 2011, 17, 9494-9502.

[26] P. Wu, P. Du, H. Zhang, C. Cai, Phys. Chem. Chem. Phys. 2013, 15, 6920-6928.

[27] M. J. Burkitt, R. P. Mason, Proc. Natl. Acad. Sci. USA 1991, 88, 8440-8444; S. Navalon, Martin, R., Alvaro, M., Garcia, H., ChemSusChem 2011, 4, 650-657; S. Navalon, D. Sempere, M. Alvaro, H. Garcia, Appl. Mater. Interfaces 2013, 5, 7160-7169.

[28] P. Slobodian, P. Riha, P. Cavallo, C. A. Barbero, R. Benlikaya, U. Cvelbar, D. Petras, P. Saha, J. Nanomater. 2014, 2014, Article ID 589627; J. Zhang, H. Zou, Q. Qing, Y. Yang, Q. Li, Z. Liu, X. Guo, Z. Du, J. Phys. Chem. B 2003, 107, 3712-3718; D. B. Mawhinney, V. Naumenko, A. Kuznetsova, J. J. T. Yates, J. Am. Chem. Soc. 2000, 122, 2383-2374. 


\section{Entry for the Table of Contents}

\section{COMMUNICATION}

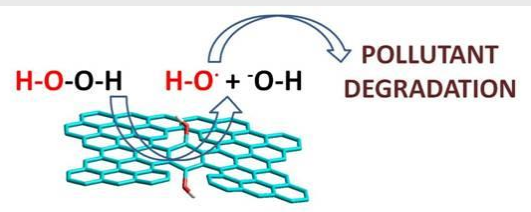

CARBOCATALYSIS

Graphenes are highly efficient metal-free carbocatalysts for the generation of hydroxyl radicals in water
Juan C. Espinosa, Sergio Navalón, Ana Primo, Mónica Moral, Javier Fernández Sanz, Mercedes Álvaro, Hermenegildo García*

Page No. - Page No.

Graphenes as efficient metal-free Fenton catalysts 